\title{
Electrophysiological indices of emotion processing during retrieval of autobiographical memories by school-age children
}

\author{
Patricia J. Bauer • Jennifer Stafford Stevens • \\ Felicia L. Jackson • Priscilla San Souci
}

Published online: 2 December 2011

(C) Psychonomic Society, Inc. 2011

\begin{abstract}
We used event-related potentials (ERPs) to examine emotion processing during retrieval of emotional autobiographical memories by school-age children. We initiated processing of the emotional experiences using neutral cue words. On one-third of trials, children were instructed to think of a memory of a negative event, and on another third of trials, they were instructed to think of a memory of a positive event. We then recorded ERPs from 32 electrode sites as the children processed the emotional memories again later in the testing session. The 7- to 10year-old children generated memories appropriate to the valences specified in the instructions. Neural responses differed as a function of the emotional valence of the events associated with the cues and as a function of gender. In the sample as a whole, differential processing of positive relative to negative and neutral emotions was apparent at posterior electrode sites $1,000-1,500 \mathrm{~ms}$ after stimulus onset. For girls, the effect was apparent beginning at $500 \mathrm{~ms}$. No differences between the neural responses to negative and neutral stimuli were observed. At frontal electrode sites, girls evidenced faster processing of positive than of negative emotion, whereas boys evidenced faster processing of negative than of positive emotion. In conclusion, we discuss the possible origins of genderdifferential patterns of neural processing.
\end{abstract}

Keywords Autobiographical memory . Cue words . Emotion - Episodic memory - Emotional memory - ERPs . Gender differences

P. J. Bauer $(\varangle) \cdot$ J. Stafford Stevens $\cdot$ F. L. Jackson • P. San Souci Department of Psychology, Emory University,

Atlanta, Georgia

e-mail: patricia.bauer@emory.edu
The relation between emotion and cognition is of substantial interest in both the emotion and cognition literatures. One area in which the interaction of these systems is of particular concern is memory. Emotion has been shown to affect, for example, the accuracy (e.g., Hamann, 2001), longevity (e.g., Sharot \& Phelps, 2004), and vividness (e.g., Talarico, LaBar, \& Rubin, 2004) of memories (see LaBar \& Cabeza, 2006, for a review). Episodic memories of specific past events often are infused with the emotional reactions and responses of the individuals involved in the events. Emotional content figures especially prominently in autobiographical or personal memories and is one of the presumed sources of their longevity (e.g., Bauer, 2007; Brewer, 1996). Among adults, there is evidence of differential neural processing as a function of the emotional valence of a memory, as well as suggestive evidence of gender differences. In children, there has been relatively less research on the representation of emotional experience, and this research is only beginning to be informed by results from neuroimaging studies. The purpose of the present study was to begin to fill this gap by using event-related potentials (ERPs) to examine the neural processing of emotion by school-age children. We examined neural processing as the children thought about autobiographical or personal memories, some of which were emotional (positive and negative), and others of which were more affectively neutral. The strong representation of emotion in autobiographical memories makes them an especially attractive domain in which to examine emotion processing.

Among adults, both behavior and neural processing differ as a function of the emotional valence of an event or experience. In behavior, narratives describing negative experiences are longer, more structurally complex, and more coherent than narratives describing positive experiences. Narratives about negative experiences also contain 
more negative emotion and cognitive-processing words (e.g., Bohanek, Fivush, \& Walker, 2004; Fivush, Bohanek, Marin, \& Sales, 2008; Pennebaker \& Francis, 1996).

Different types of emotional experiences also seem to be represented differently at the neural level. Most germane to the present research are differences in ERPs (for reviews of findings from fMRI studies, see, e.g., Cabeza, Prince, Daselaar, Greenberg, Budde, Dolcos, \& Rubin, 2004; Daselaar, Rice, Greenberg, Cabeza, LaBar, \& Rubin, 2008). Much of the research has focused on neural processing while viewing pictures from the International Affective Picture System (IAPS; Lang, Bradley, \& Cuthbert, 2005). Differential responses to arousing stimuli are seen in two ERP components. The early posterior negativity is apparent as few as $150 \mathrm{~ms}$ after stimulus onset and is more pronounced for more arousing stimuli (positive or negative). It is prominent at bilateral temporo-occipital sites (e.g., Junghöfer, Sabatinelli, Bradley, Schupp, Elbert, \& Lang, 2006; Schupp, Junghöfer, Weike, \& Hamm, 2003; Schupp, Öhman, Junghöfer, Weike, Stockburger, \& Hamm, 2004). The early posterior negativity is followed by a sustained late positive potential. The late positive potential is apparent for both positive and negative stimuli (e.g., Cuthbert, Schupp, Bradley, Birbaumer, \& Lang, 2000; Dolcos \& Cabeza, 2002), earning it the name the emotion effect. The emotion effect is seen as early as $200-300 \mathrm{~ms}$ after stimulus onset, and it persists beyond stimulus offset. The effect is maximal at parietal and posterior midline sites (see, e.g., Cuthbert et al., 2000; Hajcak \& Olvet, 2008). At parietal sites, the effect emerges at approximately the same time for positive and negative stimuli (Dolcos \& Cabeza, 2002). At midline and frontocentral sites, differential processing of positive and neutral stimuli is apparent earlier (300-800 ms) than differential processing of negative and neutral stimuli (beginning at 700-800 ms). During the earlier epoch, the processing of positive stimuli differs from that of negative and neutral stimuli, whereas in the later epoch, the processing of positive and negative stimuli no longer differs (e.g., Cuthbert et al., 2000; Dolcos \& Cabeza, 2002). In a test of memory for emotional stimuli, Maratos and Rugg (2001) observed a long-duration (800-1,944 ms) positivity in response to items from negative encoding contexts (positive items were not included; see also Smith, Dolan, \& Rugg, 2004).

The study of the representation and expression of the emotional aspects of experience in children lags behind such study in adults. One reason is that much developmental research has focused on assessments of intensely negative, and even traumatic, events such as hurricanes (e.g., Fivush, Sales, Goldberg, Bahrick, \& Parker, 2004) and on painful medical procedures such as a voiding cystourethrogram (Quas, Goodman, Bibrose, Pipe, Craw, \& Ablin, 1999). Such studies do not afford direct comparisons of differently valenced events. The few studies that have directly compared the narrative representation of positive and negative events have indicated that, as among adults, children's narratives describing negative events are more coherent and focus more on causes and explanations than do narratives describing positive events (e.g., Ackil, Van Abbema, \& Bauer, 2003; Bauer, Stark, Lukowski, Rademacher, Van Abbema, \& Ackil, 2005; Burch, Austin, \& Bauer, 2004; Sales, Fivush, \& Peterson, 2003).

Relative to the literature for adults, the body of work on the neural representation of emotional experience in children is small. Pickens, Field, and Nawrocki (2001) recorded electroencephalograms (EEGs) while preschool-age children watched videotaped vignettes of children experiencing happy, sad, angry, and fearful events. The researchers observed EEG asymmetry in frontal regions during all four types of vignettes. Hajcak and Dennis (2009) used ERPs to examine neural processing as 5- to 10-year-old children viewed developmentally appropriate pictures from the IAPS. The children did not display the differential early posterior negativity typically observed in adults. However, the late positive potential was apparent. As in adults, the late positive potential was larger for both pleasant and unpleasant stimuli at midline centroparietal sites.

In the present study, we added to the small body of research with children by recording ERPs as 7- to 10-yearolds processed emotional events elicited by neutral cue words. In the cue word technique, participants are given words (e.g., rain, chair, picture) and are asked to "think of a specific memory" associated with each. The technique has been used extensively with adults to examine the shape of the distribution of memories across the lifespan (e.g., Rubin, 1982; Rubin, Wetzler, \& Nebes, 1986) and to elicit emotional processing in the context of fMRI (Greenberg, Rice, Cooper, Cabeza, Rubin, \& LaBar, 2005). Relative to techniques using other emotional stimuli (e.g., emotionally arousing photos), it supports processing of materials that may be especially personally significant to the participant not only in the moment - as the stimulus is perceived - but in personal or autobiographical history. In adults, retrieval of autobiographical memories is accompanied by a sense of reliving of the event and, thus, the emotion (e.g., Tulving, 2002). Adults give high ratings of vividness and intensity as they think about these memories (see Rubin, 2005, for a discussion). Children show earlier approximation of adult levels of recognition of autobiographical memory stimuli relative to less personally relevant stimuli (Pathman, Samson, Dugas, Cabeza, \& Bauer, in press).

Outside of the domain of emotion, the utility of the cue word elicitation task for school-age children has been demonstrated in Bauer, Burch, Scholin, and Güler (2007), in which 7- to 10-year-old children provided brief narrative 
descriptions of past personal events in response to cue words. In the present research, we used the technique to elicit affectively positive and negative as well as neutral past events. We then recorded ERPs as the children processed the memories in response to the cue words. Because the event stimuli during the ERP recordings were personally relevant and significant, we expected that the procedure would provide a strong manipulation of emotion. The technique has the additional methodological advantage of allowing the same stimuli to be used across emotion conditions. Because the cue words are affectively neutral, the same word can be used to elicit processing of positive, negative, and affectively neutral experiences. As such, any differences in ERP responses can be attributed to the valenced content of the memories, as opposed to the features of the eliciting stimuli themselves (e.g., different pictorial stimuli in different valence conditions). To our knowledge, ours is the first study to test the efficacy of the cue word technique as a means of eliciting emotional processing in children.

We focused our inquiry on the school years because they are an especially important period during which children become increasingly proficient at expressing their own perspective on the events of their lives-including the emotional significance of events (Bauer et al., 2005) - and during which the neural structures and networks implicated in the representation of emotion and memory undergo substantial developmental change (as reviewed by Bauer, in press). The major question posed in our research was whether, like adults, children exhibit differential neural processing of emotional relative to neutral stimuli. As we reviewed earlier, as adults process emotional stimuli, they exhibit the so-called emotion effect: a sustained late positive potential that is maximal at parietal sites (e.g., Cuthbert et al., 2000; Hajcak \& Olvet, 2008). Hajcak and Dennis (2009) observed this effect in children, as well, but did not observe the early posterior negativity typically seen in adults. On the basis of these findings, we anticipated that evidence of differential processing of emotional relative to neutral stimuli would be apparent late in the recording epoch, but that early evidence of differential processing might be absent. We also anticipated that because the stimuli in the present research were personal memories, rather than emotionally charged photographs, the evidence of differential processing might come in a form other than a positive potential. Because this was the first study of its kind, we did not advance a priori hypotheses as to the precise form any differential processing might take.

A secondary question examined in the present research was whether gender differences in the neural processing of emotional stimuli would be observed in school-age children. Among adults, gender-related differences have been indicated in behavior and in neural processing as a function of the emotional valence of an event or experience. In the behavioral domain of narratives, adult females tell longer, more detailed narratives than do males (Bauer, Stennes, \& Haight, 2003; Davis, 1999; Fivush \& Buckner, 2003; Thorne \& McLean, 2002). Adult females' narratives also are more imbued with emotion than are males' (Bauer et al., 2003; Davis, 1999; see Bauer, 2007, for a review). The neural processing of emotion also differs for women and men, with women showing more robust processing of negative pictures in the left hemisphere, and men showing more robust processing of negative pictures in the right hemisphere (e.g., Gasbarri, Arnone, Pompili, Marchetti, Pacitti, Calil, \& Tomaz, 2006; Gasbarri, Arnnone, Pompili, Pacitti, Pacitti, \& Cahill, 2007). Among children, gender differences appear relatively early in the behavior of girls and boys, and the differences mimic those in adults. For example, by 4 years of age, girls' personal event narratives are richer in emotion language than are boys' (Fivush, Haden, \& Adam, 1995), and by middle childhood, girls' narratives are longer and more elaborate and emotional than are boys' (Buckner \& Fivush, 1998; Fivush, Brotman, Buckner, \& Goodman, 2000). In the domain of emotion processing, McManis, Bradley, Berg, Cuthbert, and Lang (2001) provided suggestive evidence that girls and boys process IAPS pictures differently; they observed differential skin conductance and startle reactivity as a function of picture content for girls, but not for boys. In the present research, we conducted exploratory analyses of possible gender differences in the neural processing of emotional stimuli, thereby informing as to the developmental origins of such differences among adults.

\section{Method}

\section{Participants}

A group of 24 children (13 girls, 11 boys) participated. The participants ranged in age from 7.27 to 10.91 years, with an average age of 8.91 years. The children were recruited through a database of families in a large southeastern city who had expressed interest in participating in child development studies. Of the children, 19 were reported by their caregivers to be Caucasian, and 5 were reported to be African American. An additional 16 children also participated in the study ( 8 girls) but were excluded from the data analysis because of inadequate ERP data $(n=10$; see the Data reduction: Electrophysiological Data section below), technical malfunctions preventing the completion of the session $(n=2)$, or a decision not to participate in the ERP portion of the study $(n=4)$. Upon completion of the session, parents received a $\$ 10$ gift certificate, and the children received an age-appropriate toy. 
Stimulus materials

Guided by previous studies (e.g., Bauer et al., 2007; Rubin, 1982), we selected 45 neutral common nouns as cue words. These cue words are provided in Appendix A. From the pool of 45 possible words, each child was given 30 words to use to produce 30 corresponding memories. For each child, 10 words were used to elicit memories of emotionally neutral events, 10 were used to elicit memories of positive events, and 10 were used to elicit memories of negative events. The additional 15 words served as potential replacements and were used if the child was unable to think of a memory for one of the primary cues. Across participants, each word was used equally often in each valence condition and served as both a replacement and a primary cue word.

During the memory elicitation portion of the session (see below), the cue words were presented one at a time using a Microsoft PowerPoint presentation shown on a 13-in. laptop. Each word was shown in the center of the screen in white, size 40 Arial font on a blue background. Emoticons illustrating the positive and negative elicitation conditions (e.g., $\odot, \odot)$ were positioned directly below the word. In the neutral condition, the emoticon did not have a mouth (e.g., $\odot$ ). The mouth was omitted from the emoticon in the behavioral portion so as not to emphasize emotion prior to its introduction (see the Procedure section). In the ERP portion of the session (see the Procedure), the stimuli (neutral cue words and emoticons) were presented one at a time on a 15 -in. computer screen matted within a black curtain that obstructed the participant's view of anything behind the computer screen. The appearance of the stimuli in the ERP portion of the study was identical to that in the behavioral portion, with the exception that in the ERP portion, the neutral emoticon had a straight line for a mouth (e.g., $)$ ). In both the elicitation and ERP phases of the paradigm, the emoticons were used to support processing of the target emotion.

\section{Procedure}

Participants visited the laboratory for one approximately 2$\mathrm{h}$ session. Before beginning the session, the full procedure was explained to the parent and child, and both were shown the materials involved in the ERP capping (including the cap and the syringes used to apply conductive gel). Written informed consent from the parent and verbal assent from the child were obtained. All procedures were reviewed and approved by the Emory University Institutional Review Board.

The session was divided into two parts, beginning with elicitation of memories of past events in response to cue words, and ending with collection of electrophysiological (ERP) data as the children processed the memories of the emotional experiences.
Elicitation of memories in response to cue words The child was seated at a table directly across from one of two female experimenters (F.L.J. and P.S.S.). The children were reminded that they would be shown words on the computer screen, and that for each word they would be asked to tell the experimenter about an event from their lives of which the word reminded them. They were asked to generate memories from the past year, in order to increase the likelihood that the emotional experience would be remembered well. To ensure that participants understood the task before beginning, they were given a sample cue word and prompted to produce a memory of a past event in response to it. All children were able to complete the practice trial.

Each of 30 cue words was presented one at a time on the computer monitor. The emoticon appropriate to the condition was positioned below the word. Participants were instructed to read each word aloud, thus ensuring that they would be able to read the words in the ERP portion of the procedure. For each word, after the child described a past event, the experimenter asked two wh- questions (randomly selected from among Who? What? Where? When? Why?) to promote further description and elaboration of the memory. The experimenter ended the trial by repeating the cue word: "Okay, that was your memory for [insert cue word]."

The first 10 cue words were presented without any explicit instructions regarding the valence of the memories the children were to retrieve. These 10 trials constituted the neutral condition. Because emotion was not yet explicitly introduced in this phase of the study, no emotion information was conveyed in the emoticon that was positioned under each of the cue words (i.e., the mouth line was omitted). Consistent with prior research on children's autobiographical narratives (e.g., Bauer et al., 2007; Burch et al., 2004), most of the events that the children described in the neutral condition were affectively neutral, and some were mildly positive. For words in the negative condition, children were asked to think of an event when they were "unhappy" and felt "angry, sad, or upset." To further encourage retrieval of memories with the appropriate valence, a negative emoticon was positioned below each word in this condition. In the positive condition, children were asked to think of an event when they were "happy" and felt "excited, cheerful, or glad." To further encourage retrieval of memories of positive events, a positive emoticon was positioned below each cue word. In the few cases in which children began describing an event that was not consistent with the valence condition, they were stopped and asked to produce a memory of the requested valence. All participants were able to produce memories of the appropriate emotional valence. Sample narratives in response to the cue word night are provided in Appendix B. 
The order of presentation of the three valence conditions was fixed across all participants. The first 10 cue words always were in the neutral condition. Cue Words 11-15 and 21-25 were always in the negative condition, and Cue Words $16-20$ and $24-30$ were always in the positive condition. The neutral condition always was presented first because once emotion was explicitly introduced, it would be difficult to elicit memories with little or neutral emotion. Elicitation of events with negative and positive emotion was blocked so that children did not have to switch emotional states on each trial. Negative and positive emotional blocks were alternated so that children did not dwell on negative experiences, and so that the elicitation portion of the session always ended on a positive note. The cue words were randomized by order and valence within the fixed structure, such that three different random word orders were generated. The three random orders were counterbalanced across participants.

The memory elicitation portion of the session was approximately $1 \mathrm{~h}$ long and was videorecorded.

Processing of emotional experiences and recording of ERPs Following the memory elicitation procedure, children were fitted with an Advanced Neuro Technology (ANT) WaveGuard 32-channel ERP cap. The caps were made of elastic lycra; the 32 electrodes were positioned and sewn into the cap according to an adaptation of the International 10-20 system (Jasper, 1958). The electrodes were referenced online to mathematically averaged mastoids. Data were sampled at $256 \mathrm{~Hz}$ continuously using ASA computer software (ANT Software B.V., Enschede, The Netherlands). Impedances were consistently below $10 \mathrm{k} \Omega$, and generally below $5 \mathrm{k} \Omega$.

Once the cap was fitted (requiring approximately $20 \mathrm{~min}$ ), participants were seated in a chair approximately $90 \mathrm{~cm}$ in front of a monitor. The participants were reminded of the emoticons and their corresponding conditions and were explicitly shown the difference between the neutral emoticon in the behavioral stimuli and the neutral emoticon in the ERP stimuli (without and with the line representing the mouth, respectively). The participants were then told that the emoticon with the line was the same as the emoticon they had seen earlier in the session without the line, and should help remind them of the same memories. They were instructed to look at the center of the screen, and when a word was shown, to think about the positive, negative, or neutral experience they had described during the behavioral portion of the study. The cue word and emoticon stimuli occupied $0.8^{\circ}$ to $2.5^{\circ} \times 1.25^{\circ}$ of the visual field on either side of the visual midline; emoticons were positioned directly below the cue words. Participants were asked to sit as still as possible and to do their best to blink only between trials.
During ERP data collection, each of the 30 cue words (and accompanying emoticon) from the memory elicitation phase was presented four times, for a total of 120 trials (40 trials for each valence). Repeated presentation was required in order to achieve a sufficient number of trials per condition for cross-averaging. The cue words were presented in blocks of five words from the same valence condition. Trials were blocked so that children did not experience virtually constant switches in emotional valence across trials. Each quartile of 30 trials featured two fiveword blocks of cue words from each valence condition, thereby ensuring that all 30 cue words were presented before any of the cue words was repeated. Within a quartile, the five-word blocks were presented in one of three pseudorandom orders, with the constraints that no two blocks of the same valence were adjacent to one another and that all orders ended with a positive or neutral block to ensure that participants finished the session on a positive note. In total, there were 24 valence blocks throughout ERP recording: two blocks of five words each $\times$ three valence conditions to present all 30 cue words; the six blocks were repeated four times, for a total of 120 trials. The three different pseudorandom orders were presented in counterbalanced fashion across participants.

Each ERP trial consisted of a baseline that began $150 \mathrm{~ms}$ before the onset of the cue word stimulus. Each cue word was presented for $4,000 \mathrm{~ms}$, followed by an interstimulus interval that varied randomly between 6,000 and $6,200 \mathrm{~ms}$ $(M=6,100 \mathrm{~ms})$. Data were sampled throughout this period. The ERP data collection required approximately $20 \mathrm{~min}$.

\section{Data reduction}

Memory responses The narratives that the children produced during the memory elicitation portion of the session were used to assess the valence and intensity of the emotional content of the events they described in response to the cue words, and thus the effectiveness of the emotion manipulation. First, the narratives that the children produced were transcribed verbatim from video-recordings of the memory elicitation portion of the session. One child's videorecording was not available due to a technical malfunction during recording. Thus, the memory responses of 23 children were transcribed. Second, the transcripts were masked with regard to the valence of the event that the child had been instructed to remember. Masking was accomplished by removing emotion information from the prompts that the experimenters provided to elicit the memories. For example, the instruction to "Tell me a happy memory for the word dog," was changed to "Tell me a memory for the word dog." Any emotional information provided by the child her- or himself was left unchanged 
(e.g., "I was happy when I got my dog"). Third, the transcripts were ordered alphabetically by cue word, thus effectively scrambling the order of the valence conditions.

To determine the emotional valence of the events the children described, one coder, naive to the purposes and hypotheses of the study, read each narrative and categorized it as positive, negative, or neutral in emotional content. Narratives were categorized according to children's use of specific emotion terms (e.g., scared, angry, excited, happy) and affect terms (e.g., weird, hard, nice, great) and according to the emotional theme of the event. For example, narratives in which the emotion terms scared and angry were used were categorized as negative. If no emotion or affect terms were featured in the narrative, classification was determined by the culturally defined valence of the event described. For example, a description that included "receiving a gift at my birthday party" was classified as positive, whereas a description of "having a funeral for our family dog" was classified as negative.

The same naive coder also rated the narratives for emotional intensity. Intensity was rated on a scale from 0 to 3 on the basis of the extent of the description and elaboration of the emotional elements in each narrative. Narratives that made no mention of emotion received a rating of 0 . A rating of 1 was assigned when emotion was included but was not elaborated upon (e.g., "I was happy when I played basketball last week"). A rating of 2 was assigned when emotion was mentioned more than once in the narrative or when the emotion was intensified (e.g., "I was so upset at my dog's funeral"). A rating of 3 was assigned to narratives that were rich in emotional detail, such that they included a variety of emotion words with affective evaluation and/or emotional reaction to the event (e.g., "I was so happy and excited at my surprise birthday! It was the best birthday ever").

To assess the reliability of coding, a random selection of $25 \%$ of the transcripts were independently recoded by another individual. For emotional valence, the average interrater reliability was $87 \%$ (range $=83 \%-93 \%$ ). For emotional intensity, the average interrater reliability was determined using an interclass correlation $(r=.92)$.

Electrophysiological data The raw EEG data were first individually bandpass filtered with half-power cutoffs of 0.1 and $30 \mathrm{~Hz}$, and a roll-off of $24 \mathrm{~dB} /$ octave. Electrodes with off-scale readings were removed. No more than two electrodes were removed from any participant's data (max loss $=6.25 \%$ of total electrodes), and electrodes were always removed in hemisphere-matched pairs (e.g., if T7 was removed, T8 was also removed). Missing data resulting from the discarding of electrode sites were not replaced. Therefore, in the statistical analyses of the ERP data, some analyses included fewer children than the full sample; degrees of freedom were adjusted accordingly. The data then were processed with independent-component analysis using EEGLAB 6.03b (Delorme \& Makeig, 2004; available at www.sccn.ucsd.edu/eeglab) running under MATLAB 7.7.0 (The MathWorks, Natick, MA) to remove eye-blink and saccade artifacts. The EEG data for each participant were individually baseline corrected, and trials containing amplitudes that exceeded $\pm 150 \mu \mathrm{V}$ (typically caused by excessive movement or muscle activity) were rejected. Participants with 20 or more usable ERP trials in each valence condition (i.e., $50 \%$ of the 40 possible trials in each condition) were included in the sample $(n=10$ participants did not meet this threshold; their data were excluded from further analysis). Across participants, we created separate grand averages for trials in the positive, negative, and neutral conditions.

Guided by the existing literature (e.g., Cuthbert et al., 2000; Dolcos \& Cabeza, 2002; Hajcak \& Dennis, 2009) and by inspection of the data, we identified three electrode clusters of interest: posterior-lateral (P3, P4, P7, and P8), frontal-lateral (F3, F4, FC1, and $\mathrm{FC} 2)$, and frontal-midline (Fz and $\mathrm{Cz}$ ). Within each cluster, we identified specific windows of interest. In the posterior-lateral cluster, we defined middle-latency and long-latency windows (500800 and 1,000-1,500 ms, respectively). For the frontallateral and frontal-midline clusters, the middle- and longlatency windows were $500-1,000$ and $1,000-1,500 \mathrm{~ms}$, respectively. Within these windows, the dependent measure was mean amplitude. In addition, guided by findings of differences in the latencies of the emotion effect (e.g., Dolcos \& Cabeza, 2002), for the frontal-lateral and frontalmidline clusters we also identified an early window (300$500 \mathrm{~ms}$ ), in which we examined peak amplitude and latency to peak amplitude.

The existing literature features analysis of electrical activity in windows before and after those selected for examination in the present research. First, in studies with adults, an early posterior negativity to arousing stimuli (positive or negative) has been apparent as few as $150 \mathrm{~ms}$ after stimulus onset, bilaterally over temporo-occipital sites (e.g., Junghöfer et al., 2006; Schupp et al., 2003; Schupp et al., 2004). An early posterior negativity has not been observed in children, however (see Hajcak \& Dennis, 2009). In the present research, visual examination of the most relevant electrode sites (O1, O2; P7, P8; and T7, T8) provided no suggestion of an early posterior negativity effect. At the occipital and lateral-posterior sites, activity in the 150 - to $300-\mathrm{ms}$ window was positive rather than negative and did not suggest differential processing as a function of valence condition. The temporal electrode sites featured negative deflections in this window, but they also did not suggest valence condition differences. In light of the lack of evidence of an early posterior negativity, and to 
avoid inflation of the experiment-wise error rate, we did not conduct formal analyses of this activity. Second, some ERP studies with adults have featured analysis of data beyond $1,500 \mathrm{~ms}$ (e.g., Smith et al., 2004, in which the stimuli were displayed for several seconds). In the present research, we did not extend the analysis beyond $1,500 \mathrm{~ms}$, both because emotion effects may have resolved by that time (e.g., Hajcak \& Dennis, 2009) and because we observed a return to baseline levels of processing by roughly $1,700 \mathrm{~ms}$.

\section{Results}

The results are presented in two sections. The first concerns the children's behavioral (verbal) responses to the word cues during the elicitation phase of the study, and the second focuses on the ERP responses as children processed memories of emotional events. Within the latter section, we first tested for effects analogous to the posterior "emotion effect," followed by examination of possible emotion differences at frontal leads.

\section{Behavior in response to cue words}

All children provided responses to 30 cue words. In their responses to the first 10 cue words (the neutral condition), the children described emotionally neutral to mildly positive past events. In their responses to the 10 cue words to which they were to provide descriptions of "unhappy" events from the past (i.e., events during which they felt angry, sad, or upset: the negative condition), the children described emotionally negative events. Typical events in this condition were a disappointing grade or disappointing outcome of a sporting event, a fight with a friend, or a mild illness or injury. In their responses to the 10 cue words to which they were to provide descriptions of "happy" events (i.e., events during which they felt excited, cheerful, or glad: the positive condition), the children described emotionally positive events, such as a family outing or vacation, an achievement, or the addition of a new pet to the family. Planned comparisons of the ratings given the narratives by a naive coder provided support for characterization of the memory reports as reflecting neutral, negative, and positive emotion. Specifically, neutral memories $(M=0.17, S D=0.23)$ were rated as more pleasant than negative memories $(M=-0.69, S D=0.20), t(1,22)=$ $13.27, p<.001$. In turn, positive memories $(M=0.60, S D=$ 0.20 ) were rated as more pleasant than neutral memories, $t(1,22)=6.18, p<.001$.

The narratives also were rated for emotional intensity. Planned comparisons of the ratings revealed significant differences between negative $(M=0.72, S D=0.42)$ and neutral $(M=0.18, S D=0.20)$ memories, $t(1,22)=6.51$, $p<.001$, and between positive $(M=0.66, S D=0.32)$ and neutral memories, $t(1,22)=7.19, p<.001$. The ratings of negative and positive memories did not differ from one another $(p>40)$. Overall, the pattern of findings was suggestive of a successful manipulation of emotion processing. Children selected events that were consistent with the target valence, and the positive and negative memories were more emotionally arousing than the neutral memories.

Neural responses to elicited emotion

We conducted tests of ERPs using a mixed-effects implementation of the general linear model and post-hoc paired comparisons, Bonferroni corrected. The Greenhouse-Geisser correction was applied in the case of nonsphericity. Emotion, hemisphere (for lateral leads), and electrode were analyzed as within-subjects variables, and gender was analyzed between subjects.

The parietal emotion effect We tested for emotion effects at the posterior-lateral sites, where arousal-related responses have previously been observed in adults (e.g., Dolcos \& Cabeza, 2002) and in 5- to 8-year-old children (e.g., Hajcak \& Dennis, 2009). We conducted 3 (emotion: positive, negative, neutral) $\times 2$ (gender: girls, boys) $\times 2$ (hemisphere: left, right) $\times 2$ (site: central [P3, P4], lateral [P7, P8]) mixed ANOVAs for mean amplitudes within the middle-latency (500-800 ms) and long-latency (1, 000-1,500 ms) windows (gender was the only between-subjects variable).

As is suggested by inspection of Fig. 1a, consistent with our prediction, ERPs differed as a function of emotion condition. In the middle-latency window, the analysis revealed a significant main effect of emotion, $F(2,44)=$ 3.23, $p=.05$. As can be seen in Fig. 1a, less positive-going mean amplitudes in the positive relative to the neutral condition trended toward significance $(p=.08)$. No differences were observed between responses in the negative and neutral or the negative and positive conditions.

The ANOVA for the middle-latency window also revealed a significant three-way interaction between emotion, gender, and site, $F(2,44)=3.43, p=.04$. To examine the interaction, we analyzed the data for the girls and boys separately, using 3 (emotion) $\times 2$ (site) models. As is suggested by inspection of Fig. 1b, girls' ERP responses were influenced by emotion, $F(2,24)=4.83, p=.02$. Their mean amplitudes were significantly greater for negative than for positive emotion $(p=.05)$, and the difference between neutral and positive emotion approached significance $(p=.08)$. Responses in the neutral and negative conditions did not differ. There were no other significant effects for the girls. Parallel analyses for the boys revealed a significant interaction of emotion and site, $F(2,20)=9.87, p=.001$. Post-hoc analysis of the interaction 
Fig. 1 ERP waveforms for positive, negative, and neutral memories averaged across the electrode sites in the posteriorlateral cluster (P3, P4, P7, and $\mathrm{P} 8$ ). Grand averages are displayed for all participants (a) and separately for girls (b) and boys (c). The middle-latency window $(500-800 \mathrm{~ms})$ is highlighted in dark gray, and the long-latency window $(1,000-1,500 \mathrm{~ms})$ is highlighted in light gray a

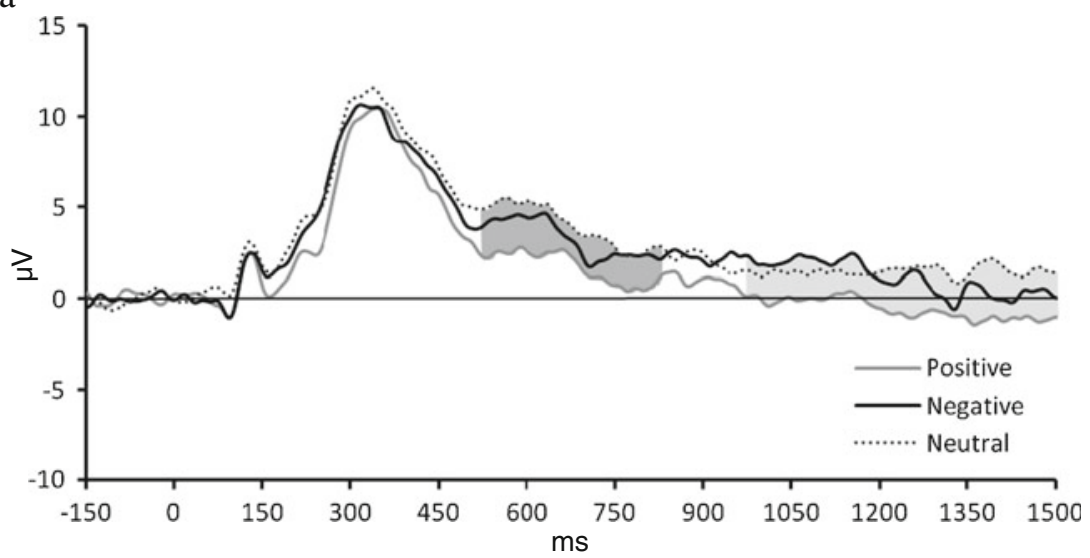

b

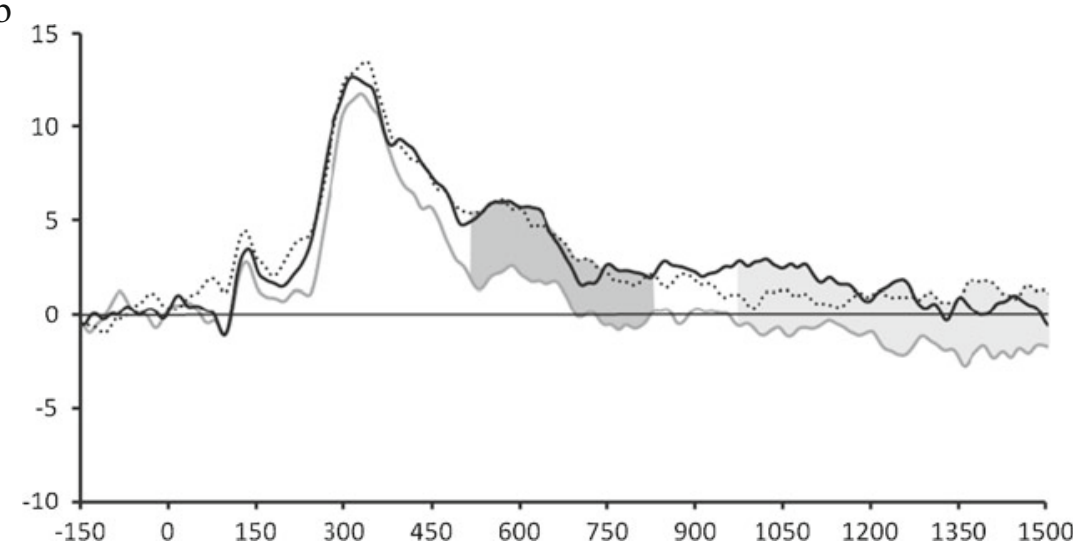

c

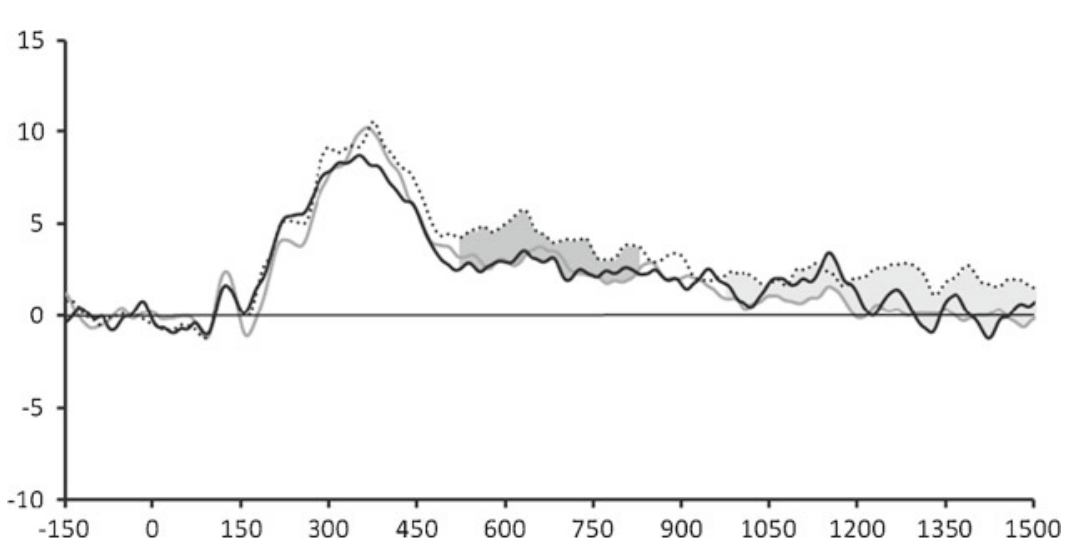

revealed no emotion effect at either pair site. Therefore, we do not interpret the interaction. In summary, in the middlelatency window, there was evidence of differential processing of emotion for girls but not for boys. The effect for girls was not the typical posterior-parietal arousal or emotion effect, but instead a "happy effect" (differential processing of positive relative to negative and neutral memories), such as is more frequently observed at midline and frontocentral sites (e.g., Cuthbert et al., 2000; Dolcos \& Cabeza, 2002).

In the long-latency window (1,000-1,500 ms), the "happy effect" continued, $F(2,44)=3.58, p=.04$. That is, as reflected in Fig. 1a, the mean amplitude was significantly larger for responses in the neutral relative to the positive condition ( $p=$ $.02)$. No differences were observed between the positive and negative conditions, or between the negative and neutral conditions $(p>.10)$. There was no interaction with hemisphere, site pair, or gender. Thus, in the long-latency window, the "happy effect" was observed across posterior sites and across gender groups (i.e., for boys as well as girls).

Frontal sites Prior research with adults has suggested an influence of emotion on ERPs at frontal sites during 
retrieval (e.g., Smith et al., 2004). To investigate this effect in children, we analyzed peak amplitude and latency to peak amplitude in an early window $(300-500 \mathrm{~ms}$, following Dolcos \& Cabeza, 2002) and mean amplitudes in middlelatency (500- to $1,000-\mathrm{ms})$ and long-latency $(1,000-$ to 1,500-ms) windows.

For the frontal-lateral sites, we used 3 (emotion) $\times 2$ (gender) $\times 2$ (hemisphere) $\times 2$ (site: frontal [F3, F4], central [FC1, FC2]) models. In the early window, no effects of peak amplitude were observed. The analysis of latencies to peak amplitude revealed an interaction of emotion and gender, $F(2,42)=3.32, p=.05$. The effect is illustrated in Fig. 2a. To examine the interaction, we conducted separate analyses for each gender group. For girls, there was no effect of emotion. For boys, however, latency to peak amplitude differed by emotion, $F(2,20)=4.68, p=.02$, since ERPs reached peak amplitude significantly earlier in the negative than in the positive condition $(p=.04)$. There were no differences between latencies to peak amplitude in the negative or positive conditions relative to the neutral condition.

At the frontal-lateral sites, there were no significant effects in the middle-latency window. In the long-latency window, emotion significantly influenced mean amplitude, $F(2,42)=3.27, p=.05$. The mean amplitude in the neutral condition was greater than the mean amplitude in the positive condition (mean $S E M \mathrm{~s}=1.86$ and $-0.92, S D \mathrm{~s}=$ 1.41 and $1.22 \mu \mathrm{V}$, respectively; $p=.01)$. No differences were observed between the neutral and negative $(M=0.13$, $S D=1.34$ ) or positive and negative conditions. No other significant effects appeared.

For the frontal-midline leads, we conducted 3 (emotion) $\times 2$ (gender) $\times 2$ (lead: $\mathrm{Fz}, \mathrm{Cz}$ ) ANOVAs for peak amplitude and latency to peak amplitude (early window only) and mean amplitude (middle- and late-latency windows). In the early window, there were no effects for peak amplitude. For latency to peak amplitude, the interaction of emotion and gender was significant, $F(2$,
Fig. 2 Average latencies to peak amplitude (in milliseconds) within the early window $(300$ $500 \mathrm{~ms}$ ) for frontal clusters, separated by valence conditions. Error bars represent \pm 1 SEM. (a) Latencies to peak amplitude for girls and boys for the frontallateral cluster. (b) Latencies to peak amplitude for girls and boys for the frontal-midline cluster

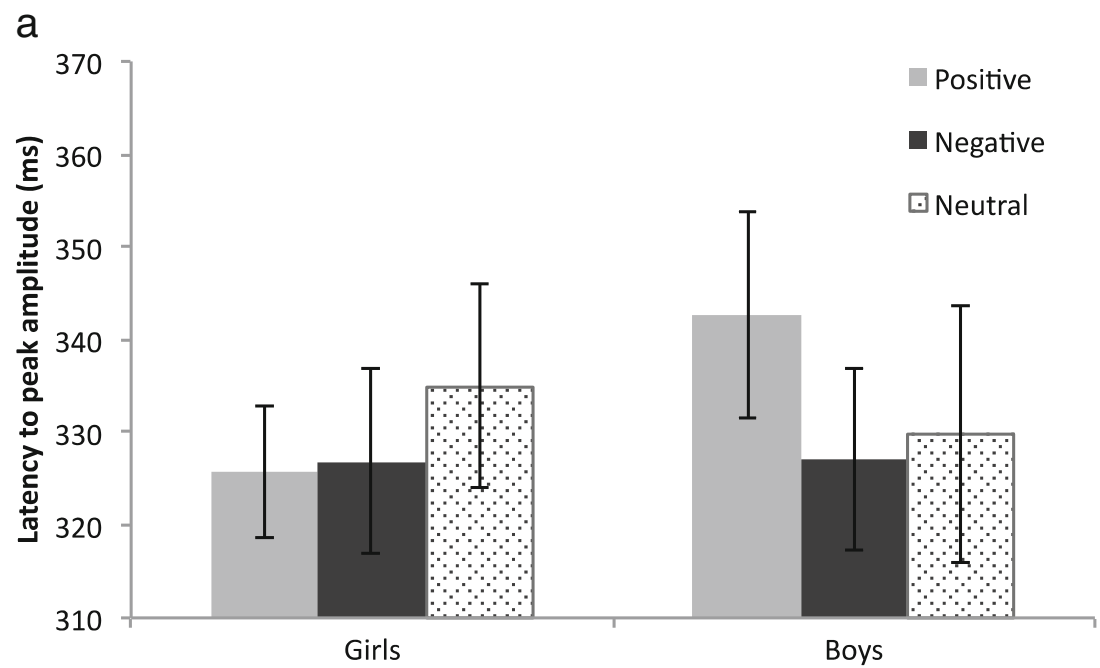

b

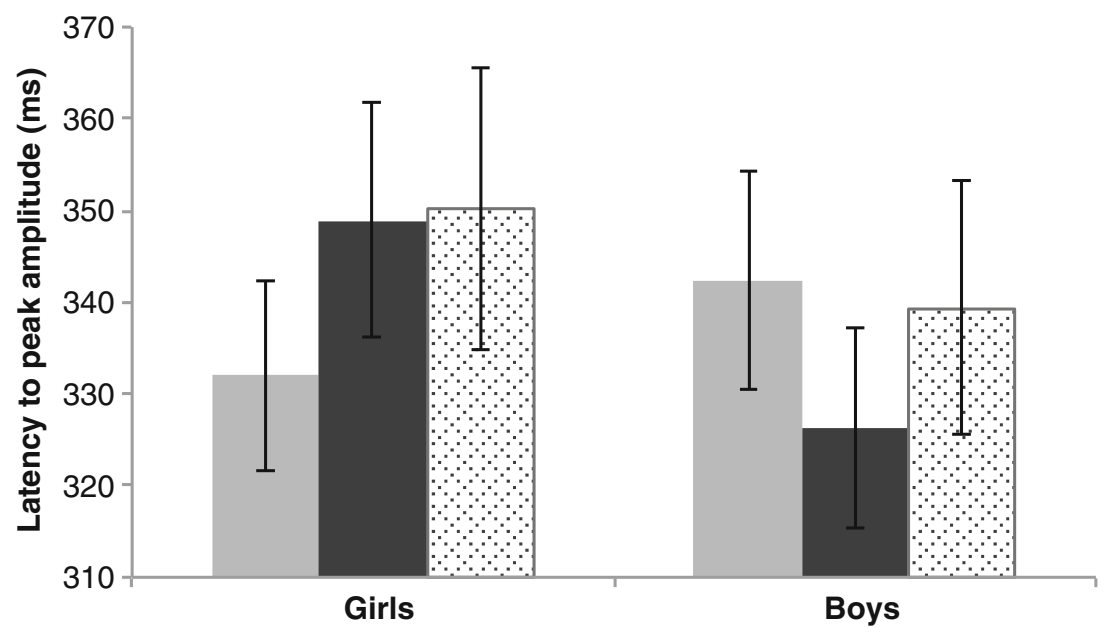


44) $=3.90, p=.03$. The effect is illustrated in Fig. 2b. To examine the interaction, we conducted separate analyses by gender. For girls, the emotion effect approached significance, $F(2,24)=3.15, p=.06$. Girls' latencies to peak amplitude occurred earlier in the positive than in the negative condition $(p=.03)$. There were no differences between latencies to peak amplitude in the positive relative to the neutral condition, or in the negative relative to the neutral condition. For boys, although the emotion effect was not significant $(p=.18)$, the pattern was the same as we had observed in the frontal-lateral cluster: namely, earlier latencies to peak amplitude in the negative than in the positive condition.

As was the case for the frontal-lateral leads, for the frontal-midline leads, there were no significant effects in the middle-latency window. In the long-latency window, we observed a significant interaction of emotion and gender, $F(2,44)=3.21, p=.05$. Separate analyses by gender revealed no significant effect of emotion for girls (Fig. 3b). For boys, mean amplitude varied by emotion condition, $F(2,20)=9.56, p=.001$. As reflected in Fig. 3c, the effect was consistent with an arousal-related influence on emotion processing. That is, the mean amplitude was significantly larger in the neutral condition than in the positive and negative conditions, which did not differ from each other. There were no other significant effects.

\section{Discussion}

The primary purpose of the present research was to use ERPs to examine the neural processing of emotion in school-age children. The emotional stimuli were children's autobiographical or personal memories. We elicited the memories using neutral cue words and then recorded ERPs as the children thought about the memories once again later in the same testing session. The 7- to 10-year-old children generated memories that were appropriate to the valence specified in the instructions, and their neural responses as they processed the emotional stimuli differed as a function of valence and of gender.

For the sample as a whole, we observed emotion effects at the posterior-lateral electrode sites. The region is the same one at which adults exhibit emotion effects as they process visual stimuli, and the same one that has been observed in the limited literature on children. In the existing literature among adults, ERPs to visually presented emotional stimuli (positive and negative) differ from those to neutral stimuli as early as $200-300 \mathrm{~ms}$ after stimulus onset. The so-called emotion effect persists beyond stimulus offset and is maximal at posterior leads (e.g., Cuthbert et al., 2000; Hajcak \& Olvet, 2008). At retrieval, items from negative encoding contexts have been observed to elicit a long-duration (800-1,944 ms) positivity (e.g., Maratos \& Rugg, 2001). In children, Hajcak and Dennis (2009) observed a similar late positive potential indicating differentiation of visually presented pleasant and unpleasant stimuli relative to neutral ones.

In contrast to the prior research with both adults and children, in the present study, the posterior leads did not indicate an emotion effect per se, but rather, a "happy effect." That is, the children in the present sample showed differential neural processing in the positive relative to neutral condition, yet their processing in the negative and neutral conditions did not differ. For girls, differential processing in the positive and neutral conditions was apparent as early as $500-800 \mathrm{~ms}$ after stimulus onset; not until 1,000-1,500 ms after stimulus onset was the effect apparent in the sample as a whole (i.e., including boys). The overall pattern was reminiscent of effects observed at midline and frontocentral sites as adults view emotional visual stimuli (Cuthbert et al., 2000; Dolcos \& Cabeza, 2002). Among adults, however, the "positive" effect occurs early in processing (up to $700-800 \mathrm{~ms}$ in both Cuthbert et al., 2000, and Dolcos \& Cabeza, 2002), after which processing of both negative and positive stimuli differs from that of neutral stimuli. The fact that the patterns of neural processing in the present research are reminiscent ofbut not identical to - those reported in the existing literature is not surprising, given the number of unique features of the present research, including (a) the focus on developing children rather than mature adults, (b) the use of represented as opposed to visually present stimuli (i.e., past events vs. pictures or sentences) as the source of emotional arousal, and (c) the use of personally relevant as opposed to generic stimuli. Observation of differential ERPs under these unique circumstances speaks to the robustness of the phenomenon and should motivate further research to identify the sources of the differential effects. Especially informative would be studies that directly compare children and adults using the same paradigm and, within age groups, studies that directly compare findings with different stimulus types.

It is noteworthy that in the present research, neural processing differed in the positive and neutral conditions even though the stimuli in the neutral condition were mildly positive (i.e., the memories that the children generated were mildly positive, though ratings of both the valence and intensity of the positive and neutral memories differed in the expected directions). This trend is consistent with research on the narrative accounts that children generate to describe autobiographical events. In the autobiographical memory literature, when no explicit mention of emotion or valence is provided in the elicitation instruction, the events that children choose to describe are affectively neutral to mildly positive (e.g., Bauer et al., 2007; Burch et al., 2004). Conversely, why we failed to observe differential neural 
Fig. 3 ERP waveforms for positive, negative, and neutral memories averaged across the electrode sites in the frontalmidline cluster ( $\mathrm{Fz}$ and $\mathrm{Cz}$ ). Grand averages are displayed for all participants (a) and separately for girls (b) and boys (c). The middle-latency window $(500-1,000 \mathrm{~ms})$ is highlighted in dark gray, and the long-latency window $(1,000-1,500 \mathrm{~ms})$ is highlighted in light gray a

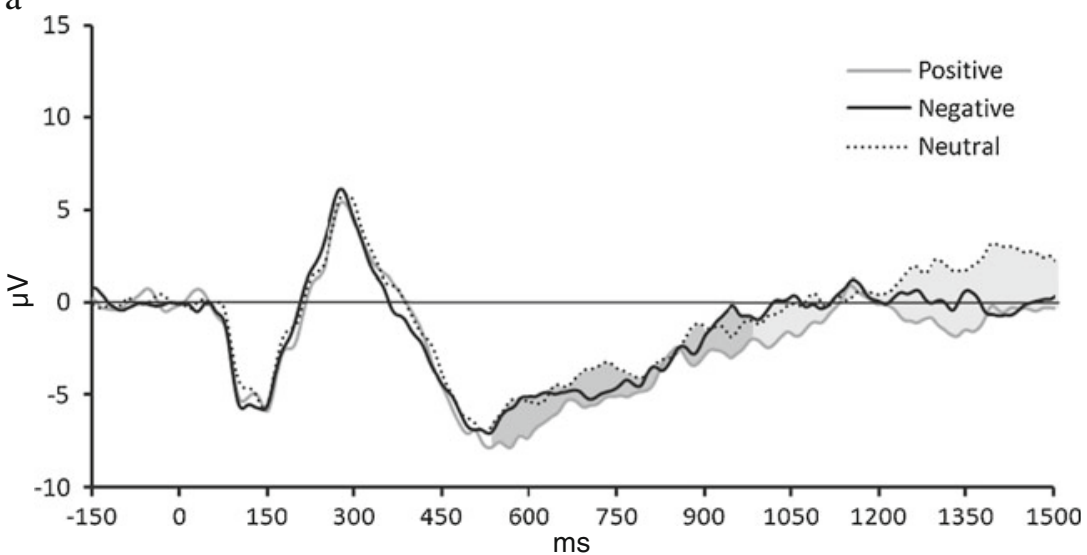

b

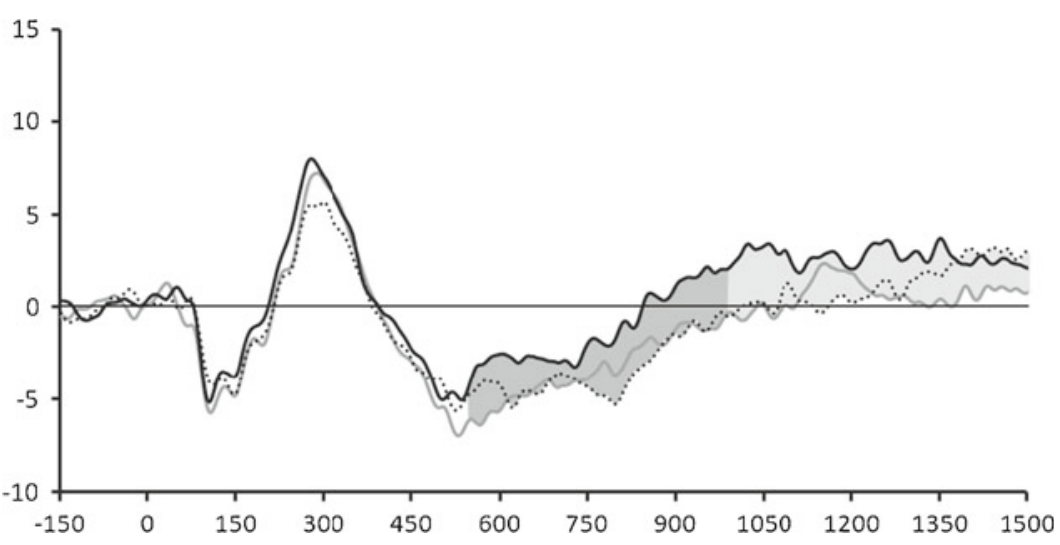

c

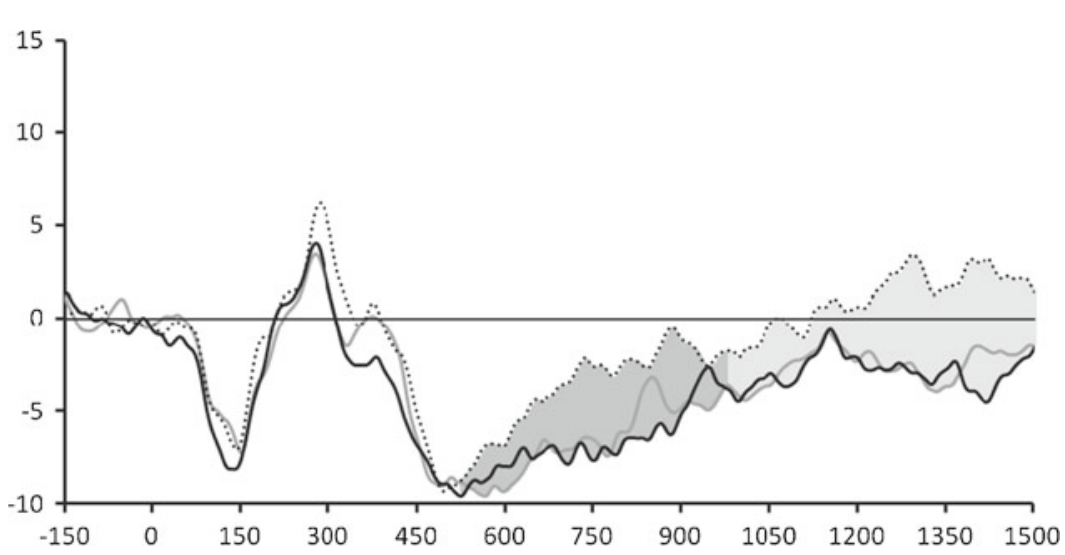

processing in the negative relative to the neutral condition is unclear. Behaviorally, the descriptions that the children provided when they were prompted to think about "unhappy" events were judged to be negatively valenced (i.e., times that the children were angry, sad, or upset). Moreover, ratings of both the valence and intensity of the events in the negative and neutral conditions differed in the expected directions. Thus, we are confident that the stimuli in the negative condition were negative. Consistent with this observation, differential neural processing of emotion in the negative and positive conditions was apparent at frontal leads (discussed below). It will be left to future research to determine whether the absence of a difference in neural processing of memories of negative and neutral events at posterior leads is a developmental phenomenon (i.e., the difference emerges with age), a cue word paradigm phenomenon (i.e., regardless of age, the neural responses to negative and neutral emotional memories elicited by cue words do not differ), or perhaps a more general autobiographical memory phenomenon (i.e., the difference is absent when individuals generate personal event memories vs. process other types of emotional stimuli). 
Prior research with adults revealed valence differences (i.e., between positive and negative stimuli) at midline and frontal electrode sites during processing of visual emotional stimuli (e.g., Cuthbert et al., 2000; Diedrich, Naumann, Maier, \& Becker, 1997; Dolcos \& Cabeza, 2002). We also observed valence differences at frontal sites in the present research. Our differences were qualified by gender. The 7- to 10-yearold girls in the sample were faster to reach peak amplitude in the positive relative to the negative condition; this effect was apparent at the frontal-midline electrode sites $(\mathrm{Fz}, \mathrm{Cz})$. In contrast, boys were faster to reach peak amplitude in the negative relative to the positive condition; this effect was apparent at the frontal-lateral electrode sites (F3, F4, FC1, FC2). Finally, boys, but not girls, evidenced an emotion (or arousal) effect at the frontal-midline electrode sites. That is, for boys, mean amplitude in the 1,000- to 1,500-ms window was greater in the neutral than in both the positive and negative conditions, which did not differ from each other.

The results of the present research are noteworthy for several reasons. First, this research is the first report in the literature of the use of cue words to elicit memories of emotional events in children. The cue word technique has been used to examine the shape of the distribution of autobiographical memories across the lifespan in adults (e.g., Rubin, 1982; Rubin \& Schulkind, 1997; Rubin et al., 1986) and children (Bauer et al., 2007). It has also been used to elicit emotional memories from adults (Greenberg et al., 2005). Extension of the paradigm to the elicitation of emotional memories in children allows for the observation of behavioral and neural responses to emotionally laden autobiographical stimuli over the course of development.

Use of the cue word technique to elicit emotional responses also has a notable advantage relative to the use of picture stimuli (such as from the IAPS: e.g., Lang et al., 2005) or videotaped vignettes of characters experiencing emotional events (e.g., Pickens et al., 2001). This advantage is that the same cue word can be used to elicit positive, negative, and neural emotional reactions in participants (see Appx. B for examples). When photos or vignettes are used, stimulus content and valence condition are confounded. Even as we highlight this potential benefit to the use of neutral cue words as stimuli, we acknowledge that in the present research, we did not fully exploit this advantage. The stimuli we used did bear an objective feature that varied across valence conditions - namely, an emoticon that designated whether the target memory was positive, negative, or neutral. The emoticons were used to aid in elicitation of the appropriate emotional response. A similar approach has been adopted in positive emission tomography studies of emotional neural activity in adults; in those studies, facial expressions consistent with a target emotion were used in conjunction with autobiographical recollection
(George, Ketter, Parekh, Herscovitch, \& Post, 1996; George, Ketter, Parekh, Horwitz, Herscovitch, \& Post, 1995). In the behavioral portion of the present research, although the emoticons were present on every trial, they were not the source of children's differential responses in the different valence conditions. Had children been responding to the emoticons only, they would not have described 30 unique past events. Yet each child did exactly that. Moreover, as is reflected in Appendix B, the narratives produced by the children strongly indicated that they had retrieved past events that had been encoded and preserved with some specificity. That is, the narratives were complete (featuring the major narrative categories of who, what, where, when, why, and how), detailed (including descriptions of specific times and locations), and vivid (featuring verbatim quotes and clear statements of emotional involvement). These results strongly imply that the paradigm elicited retrieval of specific, emotionally valenced autobiographical memories.

The emoticons also were used during ERP data collection. As with the behavioral portion of the study, we maintain that it is unlikely that the emoticons were the sole source of differences in neural responses across valence conditions. First, the emoticons were perceptually similar across the three emotion conditions: They were line drawings that varied only in the orientation of the mouth line. Although sustained increases in processing of fearful relative to neutral expressions have been observed (i.e., Eimer \& Holmes, 2002), these effects were observed only for detailed and true-to-life photographs of human faces, and not when the face stimuli were schematic emoticons, such as we used in the present research (Babiloni, Vecchio, Buffo, Buttiglione, Cibelli, \& Rossini, 2010). Second, as discussed above, the memories the children retrieved in response to the cue word prompts were complete and vivid. This strongly indicates that the memories were highly accessible to the children during the session. Although we do not have direct evidence that the memories remained at the same level of accessibility throughout ERP recording, given the personal nature of the events, the apparent strength of the representations, and the relatively brief period of time between memory elicitation and recording of the ERPs (20 min), it is reasonable to trust that they were. Overall, it thus seems logical to assume that although the emoticons used to support processing of the emotional stimuli were physically present during ERP data collection, they were not the sole source of the differential ERP effects observed in the present research.

A second noteworthy feature of the present research is that it adds to the small literature on neural processing during retrieval of emotional stimuli (e.g., Maratos \& Rugg, 2001), rather than as stimuli are presented, and appears to be the first study of processing 
during retrieval among children. As we discussed earlier, the patterns of neural processing observed in the present research differed in several ways from those observed in prior studies, thus highlighting the need for further research that would directly compare different phases of processing of the same stimuli.

Third, the present research represents what is to our knowledge the first report in the literature of the recording of ERPs during retrieval of autobiographical memories by either children or adults. To date, there have been several functional magnetic resonance imaging studies of adults' retrieval of autobiographical memories. These studies have provided critical insights into the neural structures and networks involved in the encoding and retrieval of autobiographical and emotional memories (e.g., Cabeza et al., 2004; Daselaar et al., 2008; Greenberg et al., 2005; see Hamann, 2001, and LaBar \& Cabeza, 2006, for reviews), as well as suggestions of gender-differential patterns (e.g., Cahill, 2003; Cahill, Uncapher, Kilpatrick, Alkire, \& Turner, 2004; Canli, Desmond, Zhao, \& Gabrieli, 2002). The present study is the first to reveal differences in the timing of neural processing during retrieval of differently valenced memories. It proved sensitive not only to valence but also to gender differences.

The specific nature of these gender-differential effects, and the tender age of the children in whom they were observed, raises the question of the source of genderdifferential processing of emotional autobiographical memories. Specifically, girls were found to have faster responses to positive than to negative memories, whereas boys were found to have faster responses to negative than to positive memories. In addition, the parietal-lateral "happy effect" was apparent earlier for girls than in the sample as a whole. One provocative suggestion is that gender differences in neural representation "may depend on some kind of neurobiologically (rather than socially) determined sexually dimorphic functional organization of the human brain" (Piefke, Weiss, Markowitsch, \& Fink, 2005). However, the outcome of gender-differential processing does not reveal the process by which it was established. Mature levels and patterns of neural organization emerge slowly, over the course of two decades of brain development (reviewed in Amso \& Casey, 2006). This means that there is ample time for socialization processes to leave their imprint on the developing brain.

From an early age, girls and boys are differentially socialized with respect to emotion. For example, in conversations about past events, parents use a greater number and variety of emotion words with girls than with boys (Buckner \& Fivush, 1998). Mothers, in particular, reminisce more about past emotions with daughters than with sons (Adams, Kuebli, Boyle, \& Fivush, 1995; Fivush, Berlin, Sales, Mennuti-Washburn,
\& Cassidy, 2003; Kuebli \& Fivush, 1992; Reese, Haden, $\&$ Fivush, 1996). By the time children are 6 years of age, they reflect this trend in their own behavior: Girls use a greater number and variety of emotion words than do boys (Kuebli \& Fivush, 1992). We recognize that the data are correlational and that, in all likelihood, the influences are bidirectional. For present purposes, the importance of the observation is that due to the reciprocal relations between structure and function, we have every reason to believe that socialization experiences are correlated not only with behavior, but also with neural representation. The present study cannot differentiate these possible sources of gender-differential processing, and given that complex behaviors are multiply determined, both sources of variance undoubtedly contribute. An important agenda for future research will be to examine the relations between gender-differential socialization of emotional experience and neural representation of it.

The present research also has limitations that must be acknowledged. The first is that the sample covered a wide age span of 7-10 years. The sample size was not sufficient to permit examination of both gender and age effects. In future research, it will be important to include larger samples in which possible age-related differences within the school years can be examined. A finer grain will especially be important in light of increasing evidence of neural changes that take place throughout the school years and into adolescence (e.g., Gogtay, Giedd, Lusk, Hayashi, Greenstein, Vaituzis, \& Thompson, 2004; Østby, Tamnes, Fjell, Westlye, Due-Tønnessen, \& Walhovd, 2009; Pfluger, Weil, Wies, Vollmar, Heiss, Egger, \& Hahn, 1999; Sowell, Thompson, Leonard, Welcome, Kan, \& Toga, 2004). A second limitation is that, compared to other studies of neural processing of emotional stimuli (e.g., Hajcak \& Dennis, 2009), the pool of stimuli on which the ERP responses were based was relatively small: 10 cue words per valence condition, for a total of 30 words. This limitation on the stimulus set was necessary in order not to overburden the young participants. In future research, it would be desirable to adapt the methods of the present research to permit a larger stimulus set. Third, in ERP studies of the processing of emotional stimuli, it is common (though not universal: e.g., Pickens et al., 2001) to elicit from participants ratings of their emotional responses, along dimensions of valence and arousal in particular. In the present research, mindful of the cognitive demands associated with rapid processing of autobiographical memories in response to cue words while recording ERPs, we elected not to collect this information. In future research, it would be desirable to collect ratings during the ERP, to enable assessment of whether differences in neural processing as a function of valence, gender, or both, are related to differential subjective experience of the stimulus events. 
Similarly, to remove any doubt that memory representations remained accessible throughout the session, and thus were the source of emotion processing, in future research it would be desirable to elicit reports of the memories after ERP recording and eliminate from data processing any events that children seemed unable to retrieve post-recording.

In conclusion, the present research provides a unique window on the neural correlates of emotion processing in school-age girls and boys. The work revealed differential patterns of neural responses as a function of emotional valence. The combination of the cue word and ERP techniques revealed a "happy effect" at posterior electrode sites that emerged earlier for girls than in the sample as a whole. It also revealed genderdifferential latency effects that indicated faster processing of emotionally positive relative to negative memories by girls, and faster processing of emotionally negative relative to positive memories by boys. The work provides a foundation for future research on valence and gender differences in behavior and in neural representations across development.

\section{Appendix A}

Table 1 Cue words

\begin{tabular}{lllll}
\hline ball & card & flower & kitchen & shoe \\
basket & computer & friend & money & sofa \\
bicycle & dinner & game & night & squirrel \\
bird & doctor & gift & paint & star \\
book & dog & hair & paper & street \\
bread & door & hand & picture & table \\
bridge & drink & hill & rain & teacher \\
candy & fence & house & sand & toothbrush \\
car & field & key & shirt & tree \\
\hline
\end{tabular}

\section{Appendix B: Sample narratives in response to the cue word night}

(Identifying information has been changed to protect confidentiality.)

\section{Neutral}

Child (C): Night. That reminds me of my birthday sleepover I had and we were trying to stay up all night but instead we stayed up until about 5:04.

Experimenter (E): OK can you tell me some more about that?
C: I remember, well for the first half Jenni really wanted to go to sleep so she went to sleep and then, me, Felicia, and Priscilla played downstairs for a while. And then Felicia went upstairs and we went upstairs. And Felicia went to sleep and then we read and then we turned off the lights and laid on the floor and we fell asleep like that.

E: Great. So how come you guys were trying to stay up all night?

C: We really wanted to try and see like if anyone actually could.

E: Great. And where did that happen?

C: That happened at my house.

E: At your house.

C: Yes.

E: So that's your memory for night.

Positive

C: Night. My friend Steve and me, we couldn't really go to sleep - don't worry, at the end it's a really good happy ending. And, we couldn't go to sleep, and he said, "I have an idea, we could go play the Wii." And so we went down to play the Wii, and we had lots of fun. We got snacks. And then, after about two hours, we fell asleep on the couch, then I woke him up at two o'clock in the morning and we went back upstairs, and we fell asleep.

E: Good, tell me more.

C: When my mom came in, she was like, "Did you guys sleep well?" And I was like, and I was still laying down and Steve was, and he got up and he was like, "Yea, we slept well Mrs. XXX" and I said, "Awesomely well!"

E: Good. So what were you doing when that happened?

$\mathrm{C}$ : We were looking at each other laughing after she left, because we knew that we went up and played the Wii.

E: And, how come that happened?

C: Because we couldn't go to sleep, and he had a suggestion, and I agreed to the suggestion.

E: Very good, so that's your memory for night.

Negative

C: Night. Ooh. Hmm, last year, it was super scary. Oh it was like the scariest thing ever. I . . I I was sleeping and like all these storms and stuff like that came along and this huge thunder like shook our house and I was like really scared.

E: OK. Tell me some more about that.

C: It really, well I got up in the middle of the night, trying to find my mom. And I thought it was a hurricane so I was like "Oh mommy we have to go downstairs into our hurricane spot, or our tornado spot." Because people kept saying tornadoes would come. And I was like, "No they wouldn't," and well, and then I was just like "big storms 
will come but I don't think tornadoes will come." And like no tornadoes came.

E: So, when did that happen?

C: Last year. Sometime last year.

E: Ok. And, how come you think that happened?

$\mathrm{C}$ : Because I was there.

E: Yes.

$\mathrm{C}$ : And I actually really like felt the shake.

$\mathrm{E}$ : OK so that was your memory for night.

\section{References}

Ackil, J. K., Van Abbema, D. L., \& Bauer, P. J. (2003). After the storm: Enduring differences in mother-child recollections of traumatic and nontraumatic events. Journal of Experimental Child Psychology, 84, 286-309. doi:10.1016/S0022-0965(03)00027-4

Adams, S., Kuebli, J., Boyle, P., \& Fivush, R. (1995). Gender differences in parent-child conversations about past emotions: A longitudinal investigation. Sex Roles, 33, 309-323.

Amso, D., \& Casey, B. J. (2006). Beyond what develops when: Neuroimaging may inform how cognition changes with development. Current Directions in Psychological Science, 15, 24-29.

Babiloni, C., Vecchio, F., Buffo, P., Buttiglione, M., Cibelli, G., \& Rossini, P. M. (2010). Cortical responses to consciousness of schematic emotional facial expressions: A high-resolution EEG study. Human Brain Mapping, 31, 1556-1569. doi:10.1002/hbm.20958

Bauer, P. J. (2007). Remembering the times of our lives: Memory in infancy and beyond. Mahwah, NJ: Erlbaum.

Bauer, P. J. (in press). Memory. To appear in P. D. Zelazo (Ed.), Oxford handbook of developmental psychology. New York, NY: Oxford University Press.

Bauer, P. J., Burch, M. M., Scholin, S. E., \& Güler, O. E. (2007). Using cue words to invetigate the distribution of autobiographical memories in childhood. Psychological Science, 18, 910-916. doi:10.1111/j.1467-9280.2007.01999.x

Bauer, P. J., Stark, E. N., Lukowski, A. F., Rademacher, J., Van Abbema, D. L., \& Ackil, J. K. (2005). Working together to make sense of the past: Mothers' and children's use of internal states language in conversations about traumatic and nontraumatic events. Journal of Cognition and Development, 6, 463-488. doi:10.1207/s15327647jcd0604_2

Bauer, P. J., Stennes, L., \& Haight, J. C. (2003). Representation of the inner self in autobiography: Women's and men's use of internal state language in personal narratives. Memory, 11, 27-42.

Bohanek, J. G., Fivush, R., \& Walker, E. (2004). Memories of positive and negative events. Applied Cognitive Psychology, 19, 51-66.

Brewer, W. F. (1996). What is recollective memory? In D. C. Rubin (Ed.), Remembering our past: Studies in autobiographical memory (pp. 19-66). Cambridge, U.K.: Cambridge University Press.

Buckner, J. P., \& Fivush, R. (1998). Gender and self in children's autobiographical narratives. Applied Cognitive Psychology, 12, 407-429.

Burch, M. M., Austin, J., \& Bauer, P. J. (2004). Understanding the emotional past: Relations between parent and child contributions in emotionally negative and nonnegative events. Journal of Experimental Child Psychology, 89, 276-297. doi:10.1016/j.jecp.2004.07.006

Cabeza, R., Prince, S. E., Daselaar, S. M., Greenberg, D. L., Budde, M., Dolcos, F., \& Rubin, D. C. (2004). Brain activity during episodic retrieval of autobiographical and laboratory events: An fMRI study using a novel photo paradigm. Journal of Cognitive Neuroscience, 16, 1583-1594. doi:10.1162/0898929042568578
Cahill, L. (2003). Sex- and hemisphere-related influences on the neurobiology of emotionally influenced memory. Progress in Neuro-Psychopharmacology \& Biological Psychiatry, 27, 12351241.

Cahill, L., Uncapher, M., Kilpatrick, L., Alkire, M., \& Turner, J. (2004). Sex-related hemispheric lateralization of amygdala function in emotionally influenced memory: An fMRI investigation. Learning and Memory, 11, 261-266.

Canli, T., Desmond, J. E., Zhao, Z., \& Gabrieli, J. D. E. (2002). Sex differences in the neural basis of emotional memories. Proceedings of the National Academy of Sciences, 99, 10789-10794. doi:10.1073/pnas.162356599

Cuthbert, B. N., Schupp, H. T., Bradley, M. M., Birbaumer, N., \& Lang, P. J. (2000). Brain potentials in affective picture processing: Covariation with autonomic arousal and affective report. Biological Psychology, 52, 95-111. doi:10.1016/S0301-0511(99)00044-7

Daselaar, S. M., Rice, H. J., Greenberg, D. L., Cabeza, R., LaBar, K. S., \& Rubin, D. C. (2008). The spatiotemporal dynamics of autobiographical memory: Neural correlates of recall, emotional intensity, and reliving. Cerebral Cortex, 18, 217-229. doi:10.1093/cercor/bhm048

Davis, P. J. (1999). Gender differences in autobiographical memory for childhood emotional experiences. Journal of Personality and Social Psychology, 76, 498-510.

Delorme, A., \& Makeig, S. (2004). EEGLAB: An open source toolbox for analysis of single-trial EEG dynamics including independent component analysis. Journal of Neuroscience Methods, 134, 9-21.

Diedrich, O., Naumann, E., Maier, S., \& Becker, G. (1997). A frontal positive slow wave in the ERP associated with emotional slides. Journal of Psychophysiology, 11(71), 84.

Dolcos, F., \& Cabeza, R. (2002). Event-related potentials of emotional memory: Encoding pleasant, unpleasant, and neutral pictures. Cognitive, Affective, \& Behavioral Neuroscience, 2, 252-263. doi:10.3758/CABN.2.3.252

Eimer, M., \& Holmes, A. (2002). An ERP study on the time course of emotional face processing. NeuroReport, 13, 427-431.

Fivush, R., Berlin, L., Sales, J. M., Mennuti-Washburn, J., \& Cassidy, J. (2003). Functions of parent-child reminiscing about emotionally negative events. Memory, 11, 179-192.

Fivush, R., Bohanek, J. G., Marin, K., \& Sales, J. M. (2008). Emotional memory and memory for emotions. In O. Luminet, A. Curci, \& M. Conway (Eds.), Flashbulb memories: New issues and new perspectives (pp. 163-184). New York: Psychology Press.

Fivush, R., Brotman, M., Buckner, J. P., \& Goodman, S. (2000). Gender differences in parent-child emotion narratives. Sex Roles, 42, 233-254.

Fivush, R., \& Buckner, J. P. (2003). Constructing gender and identity through autobiographical narratives. In R. Fivush \& C. Haden (Eds.), Autobiographical memory and the construction of a narrative self: Developmental and cultural perspectives (pp. 149-168). Mahwah, NJ: Erlbaum.

Fivush, R., Haden, C., \& Adam, S. (1995). Structure and coherence of preschoolers' personal narratives over time: Implications for childhood amnesia. Journal of Experimental Child Psychology, 60, 32-56.

Fivush, R., Sales, J. M., Goldberg, A., Bahrick, L., \& Parker, J. (2004). Weathering the storm: Children's long-term recall of Hurricane Andrew. Memory, 12, 104-118. doi:10.1080/ 09658210244000397

Gasbarri, A., Arnone, B., Pompili, A., Marchetti, A., Pacitti, F., Calil, S. S., \& Tomaz, C. (2006). Sex-related lateralized effect of emotional content on declarative memory: An event related potential study. Behavioural Brain Research, 168, 177184. 
Gasbarri, A., Arnnone, B., Pompili, A., Pacitti, F., Pacitti, C., \& Cahill, L. (2007). Sex-related hemispheric lateralization of electrical potentials evoked by arousing negative stimuli. Brain Research, 1138, 178-186.

George, M. S., Ketter, T. A., Parekh, P. I., Herscovitch, P., \& Post, R. M. (1996). Gender differences in regional cerebral blood flow during transient self-induced sadness or happiness. Biological Psychiatry, 40, 859-871. doi:10.1016/0006-3223(95)00572-2

George, M. S., Ketter, T. A., Parekh, P. I., Horwitz, B., Herscovitch, P., \& Post, R. M. (1995). Brain activity during transient sadness and happiness in healthy women. The American Journal of Psychiatry, 152, 341-351.

Gogtay, N., Giedd, J. N., Lusk, L., Hayashi, K. M., Greenstein, D., Vaituzis, A. C., \& Thompson, P. M. (2004). Dynamic mapping of human cortical development during childhood through early adulthood. Proceedings of the National Academy of Sciences, 101, 8174-8179. doi:10.1073/pnas.0402680101

Greenberg, D. L., Rice, H. J., Cooper, J. J., Cabeza, R., Rubin, D. C., \& LaBar, K. S. (2005). Co-activation of the amygdala, hippocampus and inferior frontal gyrus during autobiographical memory retrieval. Neuropsychologia, 43, 659-674. doi:10.1016/ j.neuropsychologia.2004.09.002

Hajcak, G., \& Dennis, T. A. (2009). Brain potentials during affective picture processing in children. Biological Psychology, 80, 333338.

Hajcak, G., \& Olvet, D. M. (2008). The persistence of attention to emotion: Brain potentials during and after picture presentation. Emotion, 8, 250-255.

Hamann, S. (2001). Cognitive and neural mechanisms of emotional memory. Trends in Cognitive Sciences, 5, 394-400.

Jasper, H. H. (1958). The ten-twenty electrode system of the International Federation. Electroencephalography and Clinical Neurophysiology, 10, 371-375.

Junghöfer, M., Sabatinelli, D., Bradley, M. M., Schupp, H. T., Elbert, T. R., \& Lang, P. J. (2006). Fleeting images: Rapid affect discrimination in the visual cortex. NeuroReport, 17, 225-229.

Kuebli, J., \& Fivush, R. (1992). Gender differences in parent-child conversations about past emotions. Sex Roles, 12, 683-698.

LaBar, K. S., \& Cabeza, R. (2006). Cognitive neuroscience of emotional memory. Nature Reviews Neuroscience, 7, 54-64.

Lang, P. J., Bradley, M. M., \& Cuthbert, B. N. (2005). International affective picture system (IAPS): Affective ratings of pictures and instruction manual (Tech. Rep. No. A-6). Gainesville, FL: University of Florida.

Maratos, E. J., \& Rugg, M. D. (2001). Electrophysiological correlates of the retrieval of emotional and non-emotional context. Journal of Cognitive Neuroscience, 13, 877-891.

McManis, M. H., Bradley, M. M., Berg, W. K., Cuthbert, B. N., \& Lang, P. J. (2001). Emotional reactions in children: Verbal, physiological, and behavioral responses to affective pictures. Psychophysiology, 38, 222-231. doi:10.1017/S0048577201991140

Østby, Y., Tamnes, C. K., Fjell, A. M., Westlye, L. T., Due-Tønnessen, P., \& Walhovd, K. B. (2009). Heterogeneity in subcortical brain development: A structural magnetic resonance imaging study of brain maturation from 8 to 30 years. Journal of Neuroscience, 29, 11772-11782.

Pathman, T., Samson, Z., Dugas, K., Cabeza, R., \& Bauer, P. J. (in press). A "snapshot" of declarative memory: Differing developmental trajectories in episodic and autobiographical memory. Memory.

Pennebaker, J. W., \& Francis, M. E. (1996). Cognitive, emotional and language processes in disclosure. Cognition and Emotion, 10, $601-626$.
Pfluger, T., Weil, S., Wies, S., Vollmar, C., Heiss, D., Egger, J., \& Hahn, K. (1999). Normative volumetric data of the developing hippocampus in children based on magnetic resonance imaging. Epilepsia, 40, 414-423.

Pickens, J., Field, T., \& Nawrocki, T. (2001). Frontal EEG asymmetry in response to emotional vignettes in preschool age children. International Journal of Behavioral Development, 25, 105-112.

Piefke, M., Weiss, P., Markowitsch, H., \& Fink, G. (2005). Gender differences in the functional neuroanatomy of emotional episodic autobiographical memory. Human Brain Mapping, 24, 313-324.

Quas, J. A., Goodman, G. S., Bibrose, S., Pipe, M.-E., Craw, S., \& Ablin, D. S. (1999). Emotion and memory: Children's long-term remembering, forgetting, and suggestibility. Journal of Experimental Child Psychology, 72, 235-270.

Reese, E., Haden, C., \& Fivush, R. (1996). Mothers, father, daughters sons: Gender differences in reminiscing. Research on Language and Social Interaction, 29, 27-56.

Rubin, D. C. (1982). On the retention function for autobiographical memory. Journal of Verbal Learning and Verbal Behavior, 21, 21-38. doi:10.1016/S0022-5371(82)90423-6

Rubin, D. C. (2005). A basic-systems approach to autobiographical memory. Current Directions in Psychology, 14, 79-83. doi:10.1111/j.0963-7214.2005.00339.x

Rubin, D. C., \& Schulkind, M. D. (1997). The distribution of important and word-cued autobiographical memories in 20-, 35-, and 70-yearold adults. Psychology and Aging, 12, 524-535. doi:10.1037/08827974.12.3.524

Rubin, D. C., Wetzler, S. E., \& Nebes, R. D. (1986). Autobiographical memory across the lifespan. In D. C. Rubin (Ed.), Autobiographical memory (pp. 202-221). Cambridge, U.K.: Cambridge University Press.

Sales, J. M., Fivush, R., \& Peterson, C. (2003). Parental reminiscing about positive and negative events. Journal of Cognition and Development, 4, 185-209. doi:10.1207/S15327647JCD0402_03

Schupp, H. T., Junghöfer, M., Weike, A. I., \& Hamm, A. O. (2003). Attention and emotion: An ERP analysis of facilitated emotional stimulus processing. NeuroReport, 14, 1107-1110. doi:10.1097/ 00001756-200306110-00002

Schupp, H. T., Öhman, A., Junghöfer, M., Weike, A. I., Stockburger, J., \& Hamm, A. O. (2004). The facilitated processing of threatening faces: An ERP analysis. Emotion, 4, 189-200. doi:10.1037/1528-3542.4.2.189

Sharot, T., \& Phelps, E. A. (2004). How arousal modulates memory: Disentangling the effects of attention and retention. Cognitive, Affective, \& Behavioral Neuroscience, 4, 294-306. doi:10.3758/ CABN.4.3.294

Smith, A. P., Dolan, R. J., \& Rugg, M. D. (2004). Event-related potential correlates of the retrieval of emotional and nonemotional content. Journal of Cognitive Neuroscience, 16, 760-775.

Sowell, E. R., Thompson, P. M., Leonard, C. M., Welcome, S. E., Kan, E., \& Toga, A. W. (2004). Longitudinal mapping of cortical thickness and brain growth in normal children. Journal of Neuroscience, 24, 8223-8231.

Talarico, J. M., LaBar, K. S., \& Rubin, D. C. (2004). Emotional intensity predicts autobiographical memory experience. Memory \& Cognition, 32, 1118-1132. doi:10.3758/BF03196886

Thorne, A., \& McLean, K. C. (2002). Telling traumatic events in adolescence: A study of master narrative positioning. In R. Fivush \& C. A. Haden (Eds.), Autobiographical memory and the construction of a narrative self: Developmental and cultural perspectives (pp. 169-186). Mahwah, NJ: Erlbaum.

Tulving, E. (2002). Episodic memory: From mind to brain. Annual Review of Psychology, 53, 1-25. doi:10.1146/annurev. psych.53.100901.135114 